\title{
Supplement to: Quantifying uncertainty on sediment loads using bootstrap confidence intervals
}

\author{
Johanna I.F. Slaets ${ }^{1}$, Hans-Peter Piepho ${ }^{2}$, Petra Schmitter $^{3}$, Thomas Hilger ${ }^{1}$, Georg \\ Cadisch $^{1}$
}

${ }^{1}$ Institute of Plant Production and Agroecology in the Tropics and Subtropics, University of Hohenheim, Garbenstrasse 13, 70599 Stuttgart, Germany

2 Biostatistics Unit, Institute of Crop Science, University of Hohenheim, Fruwirthstrasse 23, 70599 Stuttgart, Germany

${ }^{3}$ The International Water Management Institute, Nile Basin and East Africa Office, Addis Ababa, Ethiopia

Correspondence to: Johanna I.F. Slaets, Institute of Plant Production and Agroecology in the Tropics and Subtropics, University of Hohenheim, Garbenstrasse 13, 70599 Stuttgart, Germany. (hanna.slaets@gmail.com)

The objective is to simulate pairs of discharge (Q) and water level (h) that result in a stagedischarge rating curve with a fixed realized $\mathrm{R}^{2}$ (for example, $95 \%$ ). We develop the theoretical framework and provide code in SAS to obtain this result.

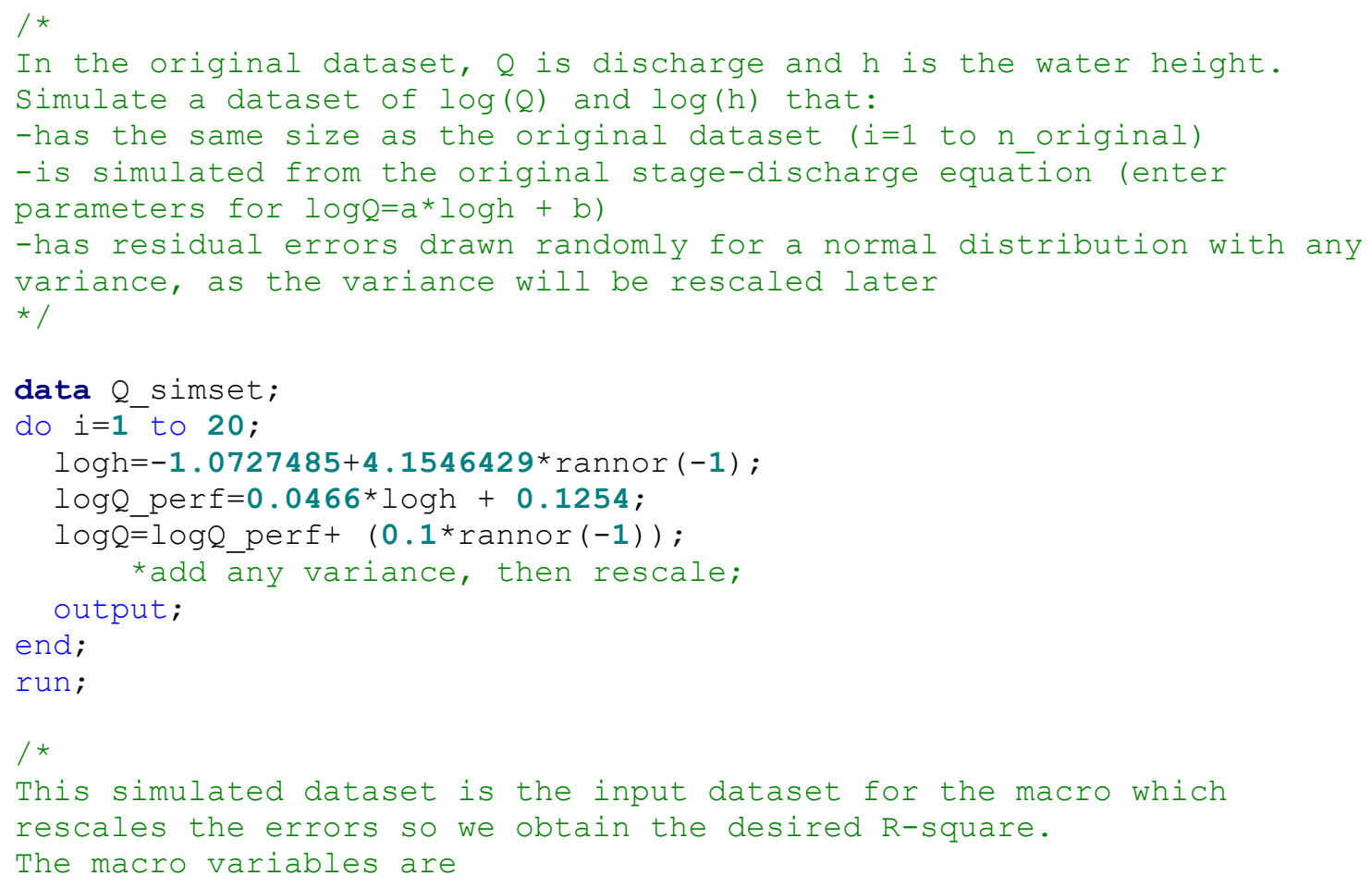




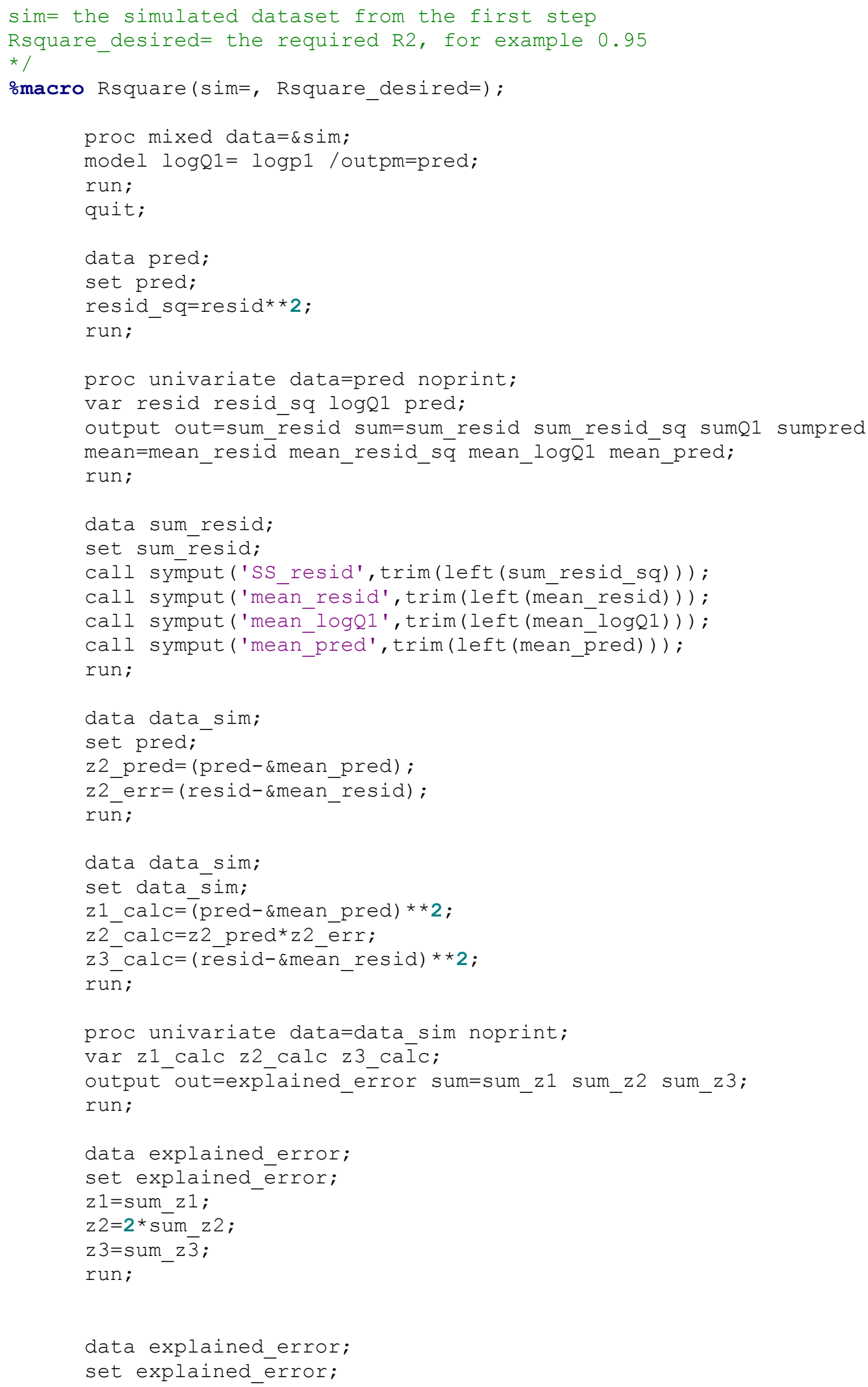




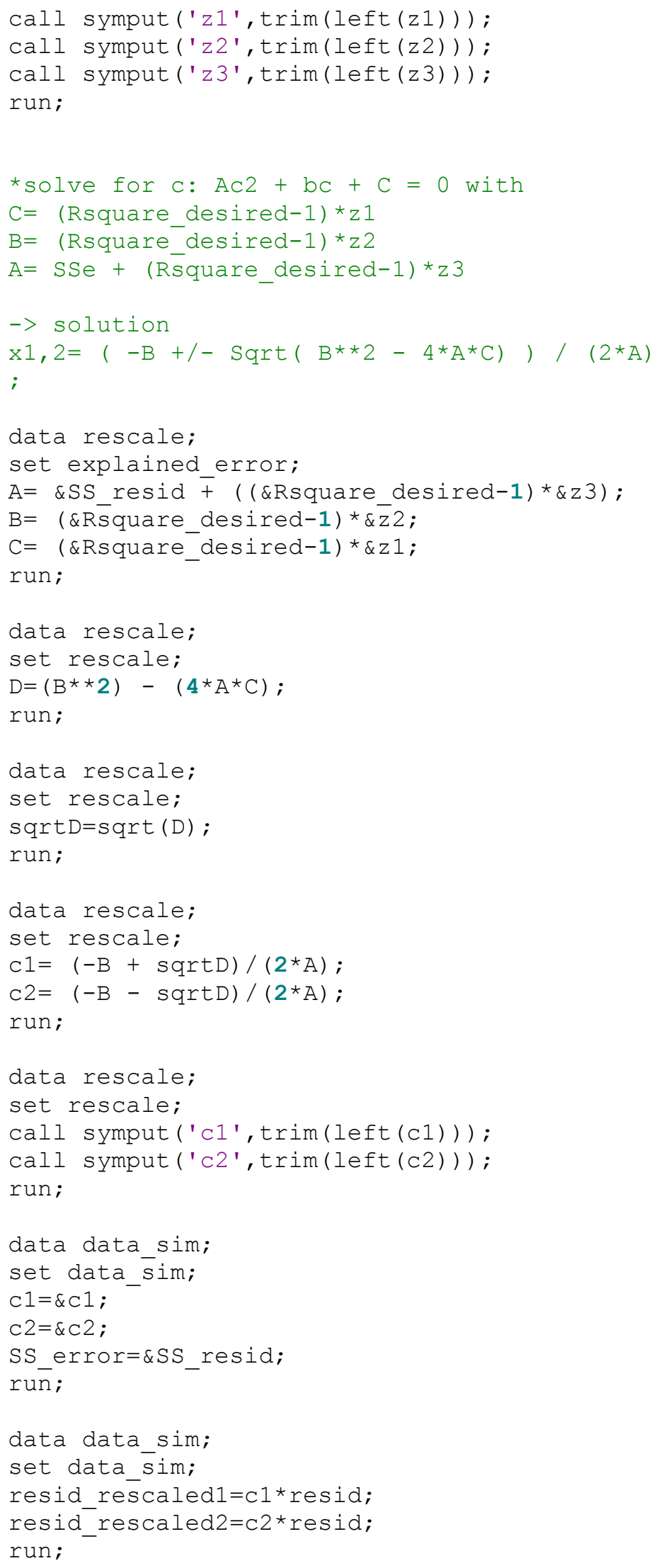




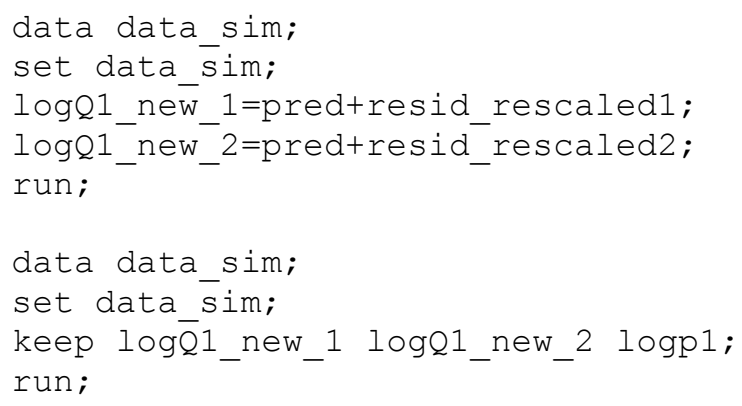

